\title{
Penerapan K-Means Clustering pada Penyakit Infeksi Saluran Pernapasan Akut (ISPA) di Kabupaten Karawang
}

\author{
Isy Karima Fauzia ${ }^{1}$, Budi Arif Dermawan ${ }^{2}$, Tesa Nur Padilah ${ }^{3}$ \\ Universitas Singaperbangsa Karawang \\ e-mail: ${ }^{1}$ isy.16121@student.unsika.ac.id, ${ }^{2}$ budi.arif@staff.unsika.ac.id, \\ ${ }^{3}$ tesa.nurpadilah@staff.unsika.ac.id \\ Diajukan: 23 Oktober 2020; Direvisi: 22 November 2020; Diterima:
}

\begin{abstract}
Abstrak
Infeksi Saluran Pernapasan Akut (ISPA) adalah penyakit yang menyerang pernapasan bawah dan pernapasan atas dapat mengakibatkan kematian. Menurut Badan Pusat Statistik Kabupaten Karawang pada tahun 2017 melaporkan 173.953 kasus ISPA dan meningkat menjadi 175.891 pada tahun 2018. Belum adanya perhatian khusus pada daerah tersebut yang menjadikan penyakit ini terus meningkat. Pada penelitian ini adalah clustering penyakit ISPA menggunakan algoritma K-Means dengan Cross-Industry Standard Process for Data Mining (CRISP-DM). Di mana pada penelitian sebelumnya menyimpulkan bahwa teknik clustering yang paling optimal adalah metode K-Means karena hasilnya lebih akurat dalam pengelompokan data dan tidak menggunakan tahap CRISP-DM. Untuk itu diperlukannya clustering daerah penyebaran ISPA yang terbagi menjadi tiga cluster yaitu rendah, sedang, dan tinggi sehingga dapat membantu dalam pengambilan kebijakan terhadap penyakit ISPA oleh pemerintah Kabupaten Karawang. Hasilnya adalah tahun 2017 terdapat 30 anggota cluster rendah, 9 anggota cluster sedang, dan 11 anggota cluster tinggi. Tahun 2018 terdapat 33 anggota cluster rendah, 5 anggota cluster sedang, dan 12 anggota cluster tinggi. Tahun 2019 terdapat 20 anggota cluster rendah, 25 anggota cluster sedang, dan 5 anggota cluster tinggi. Evaluasi algoritma K-Means menggunakan SSE pada tahun 2017 yaitu 232.6133, 2018 yaitu 207.8584, dan tahun 2019 yaitu 260.3935.
\end{abstract}

Kata kunci: Data mining, Clustering, Infeksi Saluran Pernapasan Akut, K-Means, Sum of Square Error.

\begin{abstract}
Acute Respiratory Infection (ARI) is a disease that attacks the lower respiratory and upper respiratory which can result in death. The Karawang Central Statistics Agency in 2017 reported 173,953 cases of ARI and increased to 175,891 in 2018. The lack of special attention in the area of ISPA distribution makes this disease continue to increase. In this research clustering disease ARI using the K-Means algorithm with Cross-Industry Standard Process for Data Mining (CRISP-DM). Where the previous research concluded that the mosh optimal clustering technique was the K-Means method because the results were more accurate in grouping data and did not use the CRISP-DM stage. The aim is to classify areas of ISPA distribution into three clusters, namely low, medium, and high so that they can help in making decisions about ARI by the Karawang regency government. The result is that in 2017 there were 30 rendang cluster members, 9 moderate cluster members, and 11 high cluster members. In 2018 there are 33 low cluster members, 5 medium cluster members, and 12 high cluster members. In 2019 there are 20 low cluster members, 25 medium cluster members, and 5 high cluster members. Evaluation of K-Means algorithm using SSE in 2017 is 232.6133, 2018 is 207.8584, and 2019 is 260.3935.
\end{abstract}

Keywords: Acute Respiratory Infection, Data mining, Clustering, K-Means, Sum of Square Error.

\section{Pendahuluan}

Infeksi Saluran Pernapasan Akut (ISPA) adalah penyakit yang sering terjadi pada masyarakat. ISPA bisa menyerang semua umur terutama pada anak-anak baik pernapasan bawah atau atas, dan dapat menyebabkan berbagai penyakit dari infeksi ringan sampai parah yang dapat mengakibatkan kematian [1]. Infeksi Saluran Pernapasan Akut (ISPA) yang menyerang bagian bawah pernapasan disebut pneumonia [2]. Pneumonia adalah infeksi akut yang mengenai jaringan paru-paru yang disebabkan oleh berbagai bakteri, virus, dan jamur [3]. 


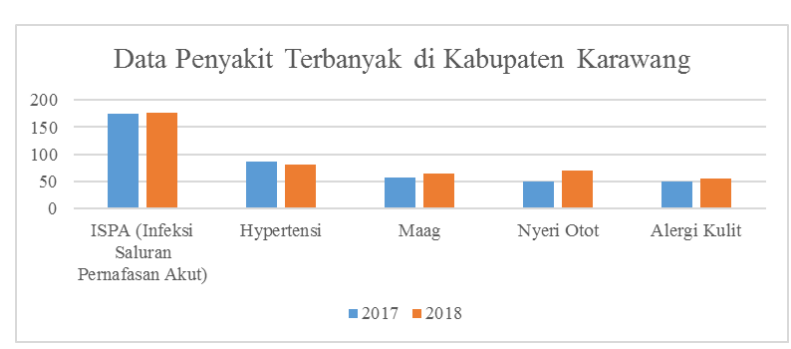

Gambar 1. Data penyakit terbanyak di Kabupaten Karawang.

Badan Pusat Statistik Kabupaten Karawang melaporkan bahwa pada tahun 2017 ditemukan kasus ISPA sebanyak 173.953 [4] dan di tahun 2018 ditemukan kasus ISPA sebanyak 175.891 [5]. Gambar 1 menunjukkan bahwa selama 2 tahun berturut-turut penyakit ISPA menjadi penyakit peringkat pertama di Kabupaten Karawang. Situasi saat ini perlakuan Dinas Kesehatan Karawang terhadap semua puskesmas sama, tidak ada perhatian khusus pada salah satu puskesmas. Oleh karena itu sebaiknya pemerintah Karawang perlu melakukan penanganan yang efektif terhadap penyakit ISPA. Dalam membantu penanganan yang efektif terhadap penyakit ISPA diperlukan suatu metode untuk menemukan daerah penyebaran penyakit ISPA di Kabupaten Karawang. Tujuannya agar pemerintah Karawang dapat memberi perhatian khusus, penanganan yang efektif, dan dapat membantu dalam pengambilan kebijakan terhadap penyakit ISPA di Kabupaten Karawang misalnya puskesmas mana saja yang memerlukan perhatian khusus atau perhatian lebih.

Beberapa penelitian yang telah dilakukan mengenai pengelompokan menggunakan algoritma KMeans. Penelitian analisis pada penyakit menular manusia di Kabupaten Majalengka disimpulkan bahwa K-Means merupakan salah satu metode clustering, alasan menggunakan algoritma K-Means mempunyai ketelitian yang optimal terhadap ukuran objek sehingga algoritma ini relatif lebih terukur dan efisien untuk pengolahan objek dalam jumlah besar [6]. Penelitian lainnya menyimpulkan bahwa teknik clustering yang paling optimal adalah metode K-Means karena hasilnya lebih akurat dalam pengelompokan data [7]. Penelitian menghasilkan pengetahuan baru daerah yang banyak terkena penyakit ISPA dengan tahap Knowledge Discovery in Database (KDD) menggunakan tool RapidMiner dan disimpulkan bahwa algoritma K-Means mendapatkan hasil yang optimal untuk pengklasteran [8].

Dari permasalahan di atas maka akan dilakukan penelitian clustering penyakit ISPA menggunakan algoritma K-Means dengan tahap Cross-Industry Standard Process for Data mining (CRISP-DM). Tool yang digunakan adalah RStudio dengan menghitung akurasi nilai error menggunakan metode SSE (Sum of Square Error). Data yang digunakan adalah data penyakit ISPA dari tahun 2017-2019 yang didapat dari Dinas Kesehatan Kabupaten Karawang dengan tipe data numerik. Penelitian ini dilakukan dengan harapan untuk mempermudah Dinas Kesehatan dalam menemukan daerah penyebaran penyakit ISPA.

\section{Metode Penelitian}

Alur penelitian diilustrasikan pada Gambar 2, yang terdiri dari 3 bagian utama yaitu data preparation, modelling, dan evaluation.

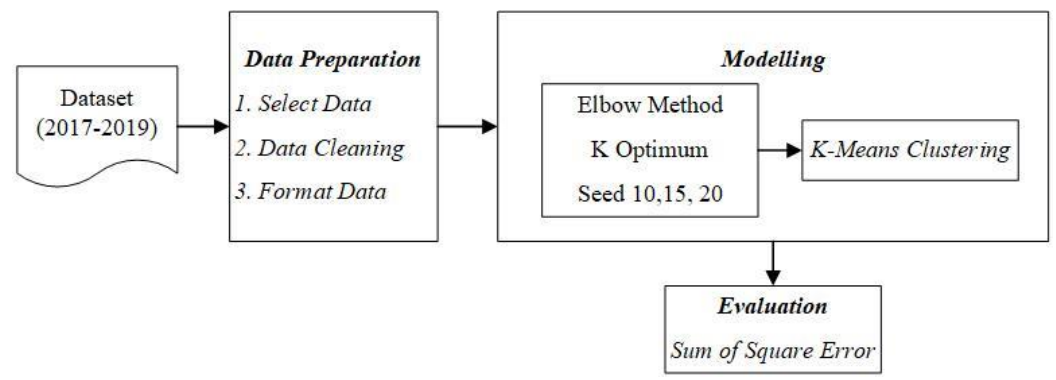

Gambar 2. Alur penelitian.

\subsection{Dataset}

Dataset yang didapatkan terdiri dari 11 variabel. Berikut adalah keterangan dataset tersebut. 
Tabel 1. Keterangan dataset.

\begin{tabular}{|c|c|c|}
\hline Tahun & Atribut & Sumber \\
\hline 2017 & $\begin{array}{l}\text { Nomor, Puskesmas, Jumlah Penduduk, Pneumonia umur }\left(<1^{\text {th }}\right) \text {, Pneumonia umur }\left(1^{\text {th }}\right. \\
\left.-<5^{\text {th }}\right) \text {, Pneumonia umur }\left(\geq 5^{\text {th }}\right) \text {, Bukan Pneumonia umur }\left(<1^{\text {th }}\right) \text {, Bukan Pneumonia } \\
\text { umur }\left(1^{\text {th }}-<5^{\text {th }}\right) \text {, Bukan Pneumonia umur }\left(\geq 5^{\text {th }}\right) \text {, Total Pneumonia, Total Bukan } \\
\text { Pneumonia }\end{array}$ & $\begin{array}{l}\text { Dinas Kesehatan Kabupaten } \\
\text { Karawang }\end{array}$ \\
\hline 2018 & $\begin{array}{l}\text { Nomor, Puskesmas, Jumlah Penduduk, Pneumonia umur }\left(<1^{\text {th }}\right) \text {, Pneumonia umur }\left(1^{\text {th }}\right. \\
\left.-<5^{\text {th }}\right) \text {, Pneumonia umur }\left(\geq 5^{\text {th }}\right) \text {, Bukan Pneumonia umur }\left(<1^{\text {th }}\right) \text {, Bukan Pneumonia } \\
\text { umur }\left(1^{\text {th }}-<5^{\text {th }}\right) \text {, Bukan Pneumonia umur }\left(\geq 5^{\text {th }}\right) \text {, Total Pneumonia, Total Bukan } \\
\text { Pneumonia }\end{array}$ & $\begin{array}{l}\text { Dinas Kesehatan Kabupaten } \\
\text { Karawang }\end{array}$ \\
\hline 2019 & $\begin{array}{l}\text { Nomor, Puskesmas, Jumlah Penduduk, Pneumonia umur }\left(<1^{\text {th }}\right) \text {, Pneumonia umur }\left(1^{\text {th }}\right. \\
\left.-<5^{\text {th }}\right) \text {, Pneumonia umur }\left(\geq 5^{\text {th }}\right) \text {, Bukan Pneumonia umur }\left(<1^{\text {th }}\right) \text {, Bukan Pneumonia } \\
\text { umur }\left(1^{\text {th }}-<5^{\text {th }}\right) \text {, Bukan Pneumonia umur }\left(\geq 5^{\text {th }}\right) \text {, Total Pneumonia, Total Bukan } \\
\text { Pneumonia }\end{array}$ & $\begin{array}{l}\text { Dinas Kesehatan Kabupaten } \\
\text { Karawang }\end{array}$ \\
\hline
\end{tabular}

\subsection{Imputasi Mean}

Imputasi dengan mean merupakan salah satu imputasi yang sering digunakan. Mean adalah mengambil nilai rata-rata dari semua nilai data yang diketahui. Metode ini hanya bisa digunakan untuk data yang berbentuk numerik saja. Untuk mendapatkan nilai mean maka digunakan dengan rumus sebagai berikut [9].

$\bar{x}=$ Nilai imputasi baris

$$
\bar{x}=\frac{\sum_{i=1}^{n} x_{i}}{n}
$$

$x_{i}=$ Nilai baris

$n$ = Banyaknya data pada atribut

\subsection{Algoritma K-Means}

K-Means merupakan salah satu algoritma clustering yang dapat digunakan untuk mengelompokkan suatu data, data yang memiliki kemiripan yang tinggi dikelompokkan dalam satu cluster sedangkan data yang memiliki karakteristik yang berbeda dikelompokkan ke dalam cluster yang berbeda [7]. K-Means termasuk ke dalam salah satu metode clustering yang berjenis non-hierarchical. Berikut adalah proses langkah-langkah dasar melakukan clustering dengan menggunakan metode K-Means [10].

1. Menentukan jumlah cluster yang ingin dibentuk dan tetapkan pusat cluster $\mathrm{k}$.

2. Pusat awal cluster (centroid) dipilih secara acak.

3. Menghitungnya menggunakan jarak setiap data input terdapat masih-masih cluster awal dengan rumus jarak Euclidean (Euclidean Distance) sampai menemukan jarak paling dekat dari setiap data dengan cluster awal. Berikut rumus persamaan Euclidean Distance:

$$
D\left(x_{i}, \pi_{i}\right)=\sqrt{\sum_{i=1}^{n}\left(x_{i}-\pi_{i}\right)^{2}}
$$

Keterangan:

$D\left(x_{i}, \pi_{i}\right)=$ Jarak antara clustering $\mathrm{x}$ dengan pusat cluster $\mu$ pada data ke-i

$x_{i} \quad=$ Bobot data ke-i pada cluster yang ingin dicari jaraknya

$\mu_{\mathrm{i}} \quad=$ Bobot data ke-i pada pusat cluster

$n \quad=$ Jumlah data

4. Kelompokkan data berdasarkan jarak yang terdekat antara data dengan cluster awal.

5. Tentukan nilai cluster awal yang baru dengan cara hitung rata-rata dari cluster yang bersangkutan dengan rumus sebagai berikut:

Keterangan:

$$
C_{k}=\frac{1}{n_{k}} \sum_{i=1}^{n} d_{i}
$$

$n_{k}=$ total data dalam cluster $\mathrm{k}$

$d_{i}=$ total pada masing-masing cluster

6. Ulangi langkah tiga sampai dengan lima sampai setiap anggota cluster tidak ada lagi yang berubah. 


\subsection{Sum of Square Error (SSE)}

Validasi data dapat diperoleh dengan menghitung nilai SSE (Sum of Square Error) dari masingmasing nilai cluster. Semakin besar jumlah cluster k maka nilai SSE akan semakin kecil [10]. Untuk menghitung SSE menggunakan rumus sebagai berikut:

$$
S S E=\sum_{K=1}^{K=n} \sum x i \in S_{k}\left\|X_{i}-C_{k}\right\|
$$

Keterangan:

$$
\begin{array}{ll}
K & =\text { total } \text { cluster } \\
X_{i} & =\text { data ke-i } \\
C_{k} & =\text { awal } \text { cluster } \\
n & =\text { total data }
\end{array}
$$

\section{Hasil dan Pembahasan}

\subsection{Data preparation}

\subsubsection{Select Data}

Data diambil tentang penyakit ISPA di Kabupaten Karawang dan disimpan dalam bentuk file Microsoft Excel. Lalu data dibersihkan dengan cara menghapus atribut-atribut yang tidak diperlukan pada penelitian yang dilakukan. Data yang dipilih adalah data yang mengenai penyakit ISPA antara tahun 20172019. Atribut yang digunakan di antaranya nama puskesmas, jumlah penduduk, kelompok pneumonia, bukan pneumonia berdasarkan usia ( $<1$ th), usia $(1$ th $-<5$ th), usia ( $\geq 5$ th), total pneumonia, dan total bukan pneumonia.

\subsubsection{Data Cleaning}

\begin{tabular}{|c|c|c|c|c|c|c|c|c|c|}
\hline \multirow{2}{*}{ Puskesmas } & \multirow{2}{*}{$\begin{array}{c}\text { Jumlah } \\
\text { Penduduk }\end{array}$} & \multicolumn{3}{|c|}{ Pneumonia } & \multirow{2}{*}{$\begin{array}{c}\text { Total } \\
\text { Pneumonia }\end{array}$} & \multicolumn{3}{|c|}{ Bukan Pneumonia } & \multirow{2}{*}{$\begin{array}{l}\text { Total Bukan } \\
\text { Pneumonia }\end{array}$} \\
\hline & & $\left(<1^{\text {th }}\right)$ & $\left(1^{\text {th }}-<5^{\text {th }}\right)$ & $\left(\geq 5^{\text {th }}\right)$ & & $\left(<1^{\text {th }}\right)$ & $\left(1^{\text {th }}-<5^{\text {th }}\right)$ & $\left(\geq 5^{\text {th }}\right)$ & \\
\hline Adiarsa & 43888 & 19 & 60 & 3 & 82 & 427 & 682 & 1185 & 2294 \\
\hline Anggadita & 23561 & 20.26 & 46 & 44 & 90 & 147.2 & 186 & 321 & 507 \\
\hline Balongsari & 17663 & 3 & 16 & 17.96 & 19 & 21 & 101 & 490 & 612 \\
\hline Batujaya & 81167 & 47 & 91 & 17.96 & 138 & 65 & 119 & 183 & 367 \\
\hline Bayur Lor & 26437 & 20.26 & 26.46 & 17.96 & 64.68 & 147.2 & 236.8 & 557.5 & 941.4 \\
\hline Ciampel & 39113 & 4 & 10 & 5 & 19 & 87 & 148 & 578 & 813 \\
\hline Cibuaya & 59649 & 117 & 127 & 116 & 360 & 89 & 142 & 286 & 517 \\
\hline Cicinde & 31165 & 24 & 52 & 24 & 100 & 282 & 512 & 1568 & 2362 \\
\hline Cikampek & 111415 & 20.26 & 26.46 & 17.96 & 64.68 & 147.2 & 236.8 & 557.5 & 941.4 \\
\hline $\begin{array}{l}\text { Cikampek } \\
\text { Utara }\end{array}$ & 36991 & 20.26 & 26.46 & 17.96 & 64.68 & 147.2 & 236.8 & 557.5 & 941.4 \\
\hline Cilamaya & 56182 & 20.26 & 26.46 & 17.96 & 64.68 & 147.2 & 236.8 & 557.5 & 941.4 \\
\hline$\ldots$ & $\ldots$ & $\ldots$ & $\ldots$ & $\ldots$ & $\ldots$ & $\ldots$ & $\ldots$ & $\ldots$ & $\ldots$ \\
\hline$\ldots$ & $\ldots$ & $\ldots$ &.. & .. & $\ldots$ & $\ldots$ & $\ldots$ & $\ldots$ & $\ldots$ \\
\hline Wadas & 49361 & 13 & 21 & 17.96 & 34 & 418 & 488 & 557.5 & 906 \\
\hline Wanakerta & 49042 & 5 & 6 & 17.96 & 11 & 28 & 121 & 946 & 1095 \\
\hline
\end{tabular}

Terdapat beberapa data yang ketika di-input kembali dalam file Excel memiliki hasil penjumlahan berbeda dengan data hardcopy. Oleh karena itu untuk dataset final menggunakan hasil penjumlahan yang dihitung pada file Excel. Pada tahap ini dilakukan proses imputasi menggunakan teknik imputasi mean.

Tabel 2. Hasil data cleaning dataset tahun 2017.

\subsubsection{Format Data}

Tahap ini memproduksi dataset akhir yang siap ditambah atau diolah dalam tool pemodelan data mining. Data yang diperoleh dari Dinas Kesehatan Kabupaten Karawang dengan hardcopy, berupa file Microsoft Excel dengan format .xlsx diubah menjadi format CSV (Comma Separated Values). Hal ini untuk mempermudah proses modeling yang akan dilakukan di RStudio.

\subsection{Modelling}

Dataset yang telah melalui tahap data preparation selanjutnya dilakukan tahap modelling. Hal pertama yang dilakukan yaitu menentukan jumlah cluster dengan menggunakan metode Elbow. Berdasarkan Gambar 3, cluster optimal yang didapat yaitu 3 cluster. 


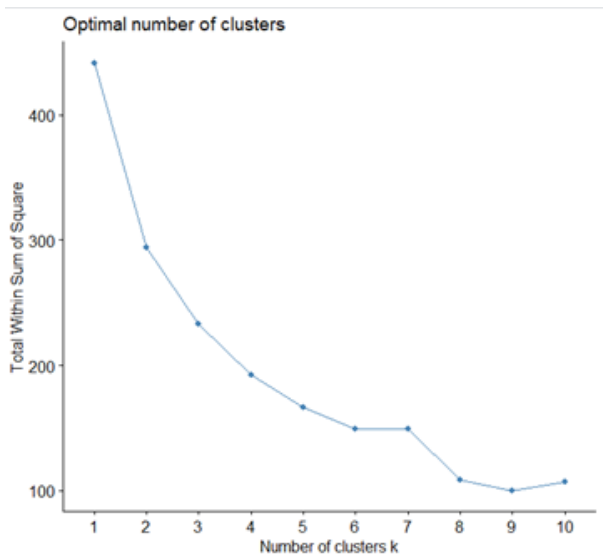

Gambar 3. Grafik cluster optimal dengan metode Elbow.

Setelah didapatkan jumlah cluster optimal, selanjutnya adalah tahap pembangunan model dengan menggunakan algoritma K-Means dengan kombinasi seed yaitu 10, 15, dan 20. Hasil terbaik dari yaitu tahun 2017 dengan seed 15, tahun 2018 dengan seed 10, dan tahun 2019 dengan seed 15. Berikut adalah plot dari tahun masing-masing.

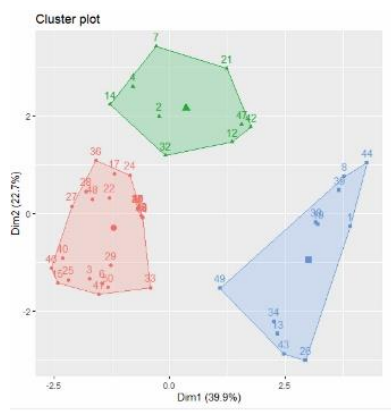

2017

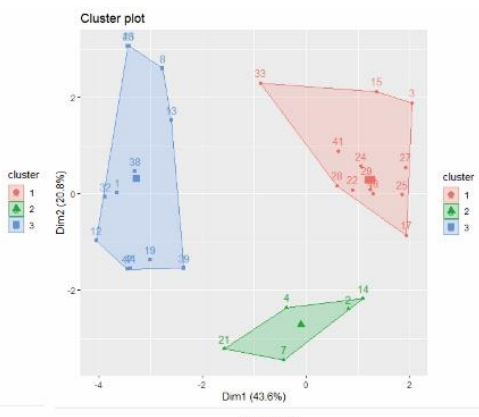

2018

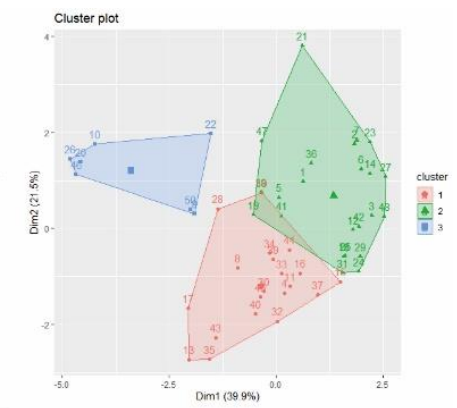

2019

Gambar 4. Plot cluster per tahun.

Pada Gambar 4 dapat dilihat bahwa titik tengah merupakan nilai centroid dari masing-masing cluster. Tahun 2017, cluster satu merupakan cluster dengan jumlah anggota terbanyak yaitu 31 anggota, cluster dua memiliki 9 anggota, dan cluster tiga memiliki 11 anggota. Sedangkan pada tahun 2018, cluster satu memiliki 33 anggota, cluster dua memiliki 5 anggota, dan cluster tiga memiliki 12 anggota. Lalu tahun 2019, cluster satu memiliki 25 anggota, cluster dua memiliki 5 anggota, dan cluster tiga memiliki 19 anggota. Berikut adalah rata-rata total kasus ISPA per tahun.

Tabel 3. Kategori ISPA per cluster.

\begin{tabular}{ccccccc}
\hline Cluster & $\mathbf{2 0 1 7}$ & Kategori & $\mathbf{2 0 1 8}$ & Kategori & 2019 & Kategori \\
\hline Cluster 1 & 1509.37 & Rendah & 1263.64 & Rendah & Sedang \\
\hline Cluster 2 & 2384.15 & Sedang & 1345.98 & Sedang & 12260.15 & Tinggi \\
\hline Cluster 3 & 5997.17 & Tinggi & 4812.92 & Tinggi & 2868.96 \\
\hline
\end{tabular}

Pada Tabel 3 dapat dilihat bahwa tidak ada perbedaan antara tahun 2017 dan 2018 . Hanya terdapat perbedaan pada tahun 2019 yaitu cluster satu dari rendah menjadi sedang, cluster dua dari sedang menjadi tinggi, dan cluster tiga dari tinggi menjadi rendah. Berikut adalah anggota dari tiap cluster. 
Tabel 4. Anggota per cluster.

\begin{tabular}{|c|c|c|c|}
\hline Tahun & Cluster 1 & Cluster 2 & Cluster 3 \\
\hline 2017 & $\begin{array}{l}\text { Balongsari, Bayur Lor, Ciampel, Cikampek, } \\
\text { Cikampek Utara, Cilamaya, Jatisari, Jayakerta, } \\
\text { Jomin, Kalangsari, Karawang, Kertamukti, Kota } \\
\text { Baru, Kutamukti, Kutawaluya, Lemah Duhur, Loji, } \\
\text { Majalaya, Medang Asem, Nagasari, Pacing, } \\
\text { Pangkalan, Pedes, Plawad, Purwasari, Sukatani, } \\
\text { Sungai Buntu, Tempuran, Tirtajaya, Tunggak Jati, } \\
\text { Wanakerta. }\end{array}$ & $\begin{array}{l}\text { Anggadita, } \\
\text { Batujaya, } \\
\text { Cibuaya, Curug, } \\
\text { Jatisari, Klari, } \\
\text { Pakisjaya, } \\
\text { Tanjungpura, } \\
\text { Tirtamulya }\end{array}$ & $\begin{array}{l}\text { Adiarsa, Cicinde, Gempol, Karawang } \\
\text { Kulon, Lemahabang, Pasirukem } \\
\text { Rawamerta, Rengsdengklok, Telagasari, } \\
\text { Telukjambe, Wadas }\end{array}$ \\
\hline 2018 & $\begin{array}{l}\text { Balongsari, Bayur Lor, Ciampel, Cikampek, } \\
\text { Cikampek Utara, Cilamaya, Jayakerta, Jomin, } \\
\text { Kalangsari, Karawang, Kertamukti, Kota Baru, } \\
\text { Kutamukti, Kutawaluya, Lemah Duhur, Loji, } \\
\text { Majalaya, Medang Asem, Nagasari, Pacing, } \\
\text { Pangkalan, Pasirukem, Pedes, Plawad, Purwasari, } \\
\text { Sukatani, Sungai Buntu, Tanjungpura, Tempuran, } \\
\text { Tirtajaya, Tunggak Jati, Wada, Wanakerta }\end{array}$ & $\begin{array}{l}\text { Anggadita, } \\
\text { Batujaya, } \\
\text { Cibuaya, Jatisarim } \\
\text { Klari }\end{array}$ & $\begin{array}{l}\text { Adiarsa, Cicinde, Curug, Gempol, } \\
\text { Karawang Kulon, Lemahabang, } \\
\text { Pakisjaya, Rawamerta, Rengasdengklok, } \\
\text { Telagasari, Teluk Jambe, Tirtamulya }\end{array}$ \\
\hline 2019 & $\begin{array}{l}\text { Batujaya, Bayur Lor, Cicinde, Cikampek, } \\
\text { Cilamaya, Gempol, Jomin, Kalangsari, Karawang } \\
\text { Kulon, Majalaya, Nagasari, Pakisjaya, Pangkalan, } \\
\text { Pasirukem, Pedes, Purwasari, Rawamerta, } \\
\text { Rengasdengklok, Sukatani, Sungai Buntu, } \\
\text { Telagasari, Teluk Jambe, Wadas, Wanakerta }\end{array}$ & $\begin{array}{l}\text { Cikampek Utara, } \\
\text { Klari, Kota Baru, } \\
\text { Lemahabang, } \\
\text { Tirtajaya }\end{array}$ & $\begin{array}{l}\text { Adiarsa, Anggadita, Balongsari, } \\
\text { Cibuaya, Ciampel, Curug, Jatisari } \\
\text { Jayakerta, Karawang, Kertamukti, } \\
\text { Kutawaluya, Lemah Duhur, Loji, } \\
\text { Medang Asem, Pacing, Plawad, } \\
\text { Tanjungpura, Tirtamulya, Tunggak Jati }\end{array}$ \\
\hline
\end{tabular}

\subsection{Evaluation}

Setelah dilakukan tahap modelling, selanjutnya adalah mengevaluasi model menggunakan Sum of Square Error (SSE). Berikut adalah hasil dari SSE.

Tabel 5. Nilai Sum of Square Error.

\begin{tabular}{cccc}
\hline Tahun & $\mathbf{S = 1 0}$ & $\mathbf{S}=\mathbf{1 5}$ & $\mathbf{S = 2 0}$ \\
\hline 2017 & 232.6891 & 232.6133 & 252.6942 \\
\hline 2018 & 207.8584 & 207.8584 & 212.4581 \\
\hline 2019 & 260.6179 & 260.3935 & 260.6179 \\
\hline
\end{tabular}

Berdasarkan Tabel 5 dapat dilihat bahwa nilai SSE terbaik tahun 2017 yaitu dengan seed 15, tahun 2018 dengan seed 10, dan tahun 2019 dengan seed 15.

\subsection{Pembahasan}

Dari hasil penelitian didapatkan bahwa tahun 2017, cluster 1 merupakan cluster dengan jumlah anggota terbanyak yaitu 31 anggota dikategorikan sebagai rendah dengan peringkat pertama total 1029 kasus, cluster 2 memiliki 9 anggota dikategorikan sebagai sedang dengan peringkat pertama total 1197 kasus, dan cluster 3 memiliki 11 anggota dikategorikan sebagai tinggi dengan peringkat pertama total 2774 kasus. Sedangkan pada tahun 2018, cluster 1 memiliki 33 anggota dikategorikan sebagai rendah dengan peringkat pertama total 769 kasus, cluster 2 memiliki 5 anggota dikategorikan sebagai tinggi dengan peringkat pertama total 169 kasus, dan cluster 3 memiliki 12 anggota dikategorikan sebagai sedang dengan peringkat pertama total 713 kasus. Lalu tahun 2019, cluster 1 memiliki 25 anggota dikategorikan sebagai sedang dengan peringkat pertama total 6541 kasus, cluster 2 memiliki 5 anggota dikategorikan sebagai tinggi dengan peringkat pertama total 2628 kasus, dan cluster 3 memiliki 19 anggota dikategorikan sebagai rendah dengan peringkat pertama total 1514 kasus. Salah satu penyebabnya adalah polusi udara dan banyaknya pabrik-pabrik yang menimbulkan polusi.

\section{Kesimpulan}

Data yang dihasilkan dalam penerapan algoritma K-Means akan mendekati ketepatan dalam pengelompokan daerah yang mempunyai kasus penyakit ISPA di Kabupaten Karawang sehingga mendapatkan perhatian khusus agar dapat mengurangi jumlah kasus ISPA di daerah tersebut. Saran untuk penelitian selanjutnya menambah variabel lain yang berhubungan dengan penyakit ISPA misalnya tingkat kepadatan penduduk, faktor lingkungan, dan sosial, dan penelitian selanjutnya bisa menggunakan algoritma lain.

\section{Daftar Pustaka}

[1] D. Maharani, F. F. Yani, and Y. Lestari, "Profil Balita Penderita Infeksi Saluran Nafas Akut Atas

Penerapan K-Means Clustering pada Penyakit Infeksi Saluran Pernapasan Akut (ISPA) di Kabupaten Karawang (Isy Karima Fauzia) 
di Poliklinik Anak RSUP DR. M. Djamil Padang Tahun 2012-2013,” J. Kesehat. Andalas, vol. 6, no. 1, pp. 152-157, 2017.

[2] S. Hayati, "Gambaran Faktor Penyebab Infeksi Saluran Pernafasan Akut (Ispa) pada Balita di Puskesmas Pasirkaliki Kota Bandung," J. Keperawatan BSI, vol. 2, no. 1, 2014.

[3] K. K. R. Indonesia, "Profil Kesehatan Indonesia 2016," Terdapat di www. depkes. go. id/.../profilkesehatan-indonesia/Profil-Kesehatan-Indonesia-2016. pdf. Diakses pada, vol. 20, 2017.

[4] B. P. S. Karawang, "Kabupaten Karawang dalam Angka 2018 (Karawang Regency in Figure)." Karawang, BPS Karawang, 2018.

[5] B. P. S. Karawang, "Kabupaten Karawang dalam Angka 2019 (Karawang Regency in Figure)." Karawang, BPS Karawang, p. 2019.

[6] A. Bastian, H. Sujadi, and P. A. Sukmana, "Rancang bangun aplikasi penilaian ujian essay dengan menggunakan algoritma nazief \& andriani dan metode cosine similarity," INFOTECH J., vol. 4, no. 2, pp. 62-68, 2018.

[7] N. Butarbutar, A. P. Windarto, D. Hartama, and S. Solikhun, "Komparasi Kinerja Algoritma Fuzzy C-Means Dan K-Means Dalam Pengelompokan Data Siswa Berdasarkan Prestasi Nilai Akademik Siswa," Jurasik (Jurnal Ris. Sist. Inf. dan Tek. Inform., vol. 1, no. 1, pp. 46-55, 2017.

[8] T. A. Sari, M. Megawaty, and A. Putra, "Pengelompokan Penyebaran Penyakit Ispa Di Wilayah Kota Sekayu Menggunakan Algoritma K-Means Clustering (Studi Kasus: Rsud Sekayu),” in Bina Darma Conference on Computer Science (BDCCS), 2019, vol. 1, no. 1, pp. 174-184.

[9] A. Izzah and N. Hayatin, "Imputasi Missing data Menggunakan Algoritma Pengelompokan Data K-Harmonic Means,” in Seminar Nasional Matematika dan Aplikasinya, 2013.

[10] A. T. Rahman, "Coal Trade Data Clustering Using K-Means (Case Study Pt. Global Bangkit Utama),” ITSMART J. Teknol. dan Inf., vol. 6, no. 1, pp. 24-31, 2017. 